\title{
Comparing the Effect of Rotor Tilt Angle on Performance of Floating Offshore and Fixed Tower Wind Turbines
}

\author{
Wongsakorn Wisatesajja ${ }^{1}$, Wirachai Roynarin ${ }^{1} \&$ Decha Intholo ${ }^{1}$ \\ ${ }^{1}$ Engineering Faculty, Rajamangala University of Technology Thanyaburi (RMUTT), Pathum Thani, Thailand \\ Correspondence: Wirachai Roynarin, Engineering Faculty, Rajamangala University of Technology Thanyaburi \\ (RMUTT), Pathum Thani, 12110, Thailand. Tel: 66-8-9771-4294. E-mail: wirachai_r@rmutt.ac.th
}

Received: July 22, 2019

Accepted: August 25, $2019 \quad$ Online Published: September 29, 2019

doi:10.5539/jsd.v12n5p84

URL: https://doi.org/10.5539/jsd.v12n5p84

\begin{abstract}
The development of Floating Offshore Wind Turbines (FOWTs) aims to improve the potential performance of the wind turbine. However, a problem arises due to the angle of tilt from the wind flow and the floating platform, which leads to a vertical misalignment of the turbine axis, thereby reducing the available blade area and lowering the capacity to capture energy. To address this problem, this paper seeks to compare the influence of the rotor tilt angle on wind turbine performance between fixed tower wind turbines and FOWTs. The models used in the experiments have R1235 airfoil blades of diameter $84 \mathrm{~cm}$. The experiment was analyzed using a wind tunnel and mathematical modelling techniques. Measurements were obtained using an angle meter, anemometer and tachometer. Testing involved wind speeds ranging from $2 \mathrm{~m} / \mathrm{s}$ to $5.5 \mathrm{~m} / \mathrm{s}$, and the rotational speeds of the two turbine designs were compared. The study found that the rotational speeds of the FOWTs were lower than those of the fixed tower turbines. Moreover, at tilt angles from $3.5^{\circ}-6.1^{\circ}$ there was a loss in performance which varied between $22 \%$ and $32 \%$ at different wind speeds. The tilt angle had a significant effect upon FOWTs due to the angle of attack was continuously changing, thus altering the optimal position of the turbine blades. This changing angle of attack caused the effective area of the rotor blade to change, leading to a reduction in power output at suboptimal angles. The study finally makes recommendations for future studies.
\end{abstract}

Keywords: floating offshore wind turbines, tilt angle, wind energy

\section{Introduction}

Fossil fuels account for more than 80 percent of global energy production, with carbon dioxide released from burning fossil fuels as one of the primary causes of climate change. There is a pressing need to reduce environmental degradation by switching to renewable energy resources such as solar energy, wind energy, geothermal energy, and biomass to produce electricity (Thorium Energy World, 2017). Renewable energy resources are unlimited, eco-friendly, and economical. The BP Statistical Review of World Energy, 2018 reported that wind power was responsible for more than half the growth in renewable energy, and had the potential to be a leading renewable energy source (BP, 2018). In 2017, overall installed wind power capacity was $539 \mathrm{GW}$, while the capacity of offshore wind turbines was 18,814 MW (Renewable Energy Network for the 21st Century [REN21], 2018). Offshore wind turbines (OWTs) were introduced to overcome the limitations of onshore wind turbines and obtain higher wind speeds while eliminating the associated visual impacts and noise concerns. To maximize performance and minimize the limitations of OWTs, such as limited suitable shallow water sites, innovations such as floating offshore wind turbines (FOWTs) have been developed to enable installation at deep water sites (National Renewable Energy Laboratory [NREL], 2011). However, FOWT performance is reduced due to the tilt angle caused by vertical misalignment of the turbine axis. The wind causes the rotor to move away from the axis; this decreases the effective area of the rotor and reduces the amount of energy captured (Ponta, Otero, \& Rajan, 2016; Gumula, Piaskowska, Pytel, \& Noga, 2017). Here, the rotor beta angle of FOWTs and rotation at wind speeds of $2-5.5 \mathrm{~m} / \mathrm{s}$ were analyzed to compare the performance of fixed tower wind turbines and FOWTs with the same airfoil blade profile and diameter.

\section{Wind Energy}

\subsection{Wind Energy Resources}

Solar radiation absorption by the earth's surface generates pressure differences. This causes air to flow from high 
pressure areas to low pressure areas creating wind. Electrical power can be generated from wind energy using a wind blade rotor connected to a drive shaft that turns a generator, thus converting kinetic energy to electrical energy. The best locations for wind farms are at the top smooth hills, round mountains, coastal areas and in the ocean (Lehr \& Keeley, 2016).

Wind turbines have a wide variety of economic, social, and environmental benefits. Electricity is essential for modern society and a renewable energy resource using wind reduces consumption of fossil fuels, preserves energy resources for future generations, and protects the environment (New Zealand Wind Energy Association, 2013). Electricity produced from wind does not cause pollution, create smog and acid rain or increase atmospheric greenhouse gases. Additionally, electricity production using wind energy has lower operating costs as the source of energy is essentially free. Furthermore, development of wind energy offers the potential to create employment opportunities in the manufacture, installation, and maintenance of wind turbines, as well as the consulting, operation, legal, and transportation services required to support the growth of wind energy markets (National Renewable Energy Laboratory [NREL], 2015).

Several limitations to using wind turbines on land include the visual impact on the surrounding ecosystem. Most wind turbines are located in remote areas due to the higher wind speeds available. This occasionally requires clearing vegetation and forests, causing significant loss of species habitat. The ecosystem may be at risk due to soil disruption and potential erosion, while the possibility also exists of increased avian mortality as a result of collisions with the wind turbine blades. The aesthetic impact of the structures and components of wind farms such as wind turbines (size, height, number, material, and color), access and site tracks, substation buildings, compounds, grid connections, anemometer masts, and transmission lines on the natural landscape are also significant factors. Noise from the gears and generators of wind turbines causes wind turbine syndrome which has an adverse impact on human health. There are two major systems that produce noise during the operational phase; the mechanical noise created by the gearbox and generator, and the aerodynamic noise created by the interaction of the turbine blades with the wind (Jaber, 2013; Lew, 2009).

FOWTs were developed to overcome the limitations of land-based wind turbines. Offshore wind resources have higher wind speeds, are less turbulent, and are more consistent in terms of availability of wind flows than onshore wind resources (Waewsak, Landry, \& Gagnon, 2015). Larger capacity wind turbines can be installed in the ocean, increasing power output by up to 40 percent compared to land-based wind turbines. Since FOWTs are located in vast ocean areas, adverse noise and visual impacts are also avoided. FOWTs are transported by simply towing the floating structures to the designated ocean site. This is potentially simpler and more economical than land-based transportation requirements (SNC-Lavalin Group, 2018). However, several limitations of FOWTs include the complexity of maintenance which is difficult, expensive and requires helicopters or boats to transport technicians and equipment. Loss of electrical power also occurs due to the distance of the FOWTs from land-based transmission lines (Burger, 2016). Several applications exist to improve the utility of FOWTs such as electrical power supply for islands, offshore drilling rigs, desalination plants, and offshore power stations for fishing boats and exploration boats (Roynarin, 2016).

Average onshore wind speeds in Thailand are around 4-5 m/s (The Department of Alternative Energy Development [DEDE], 2009). Figure 1 shows the mean wind speed at 40 meters above sea level in the Gulf of Thailand. Maximum mean wind speed is $6 \mathrm{~m} / \mathrm{s}$ but most of the area in the Gulf of Thailand has wind speeds of 4-5.5 m/s. 


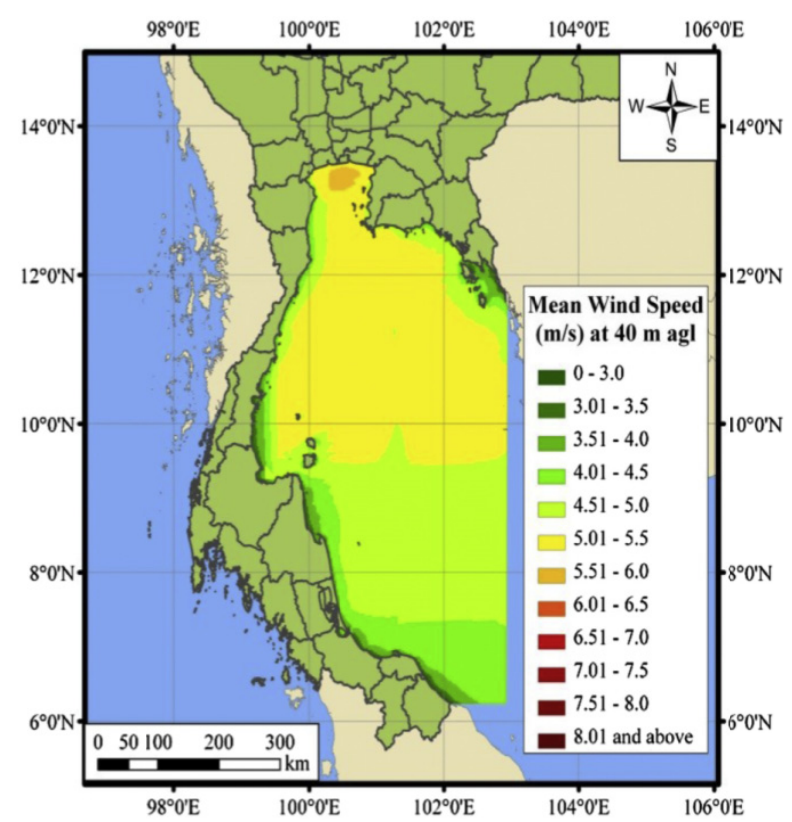

Figure 1. Mean wind speed at 40 meters above sea level in the gulf of Thailand (Waewsak et al., 2015)

\subsection{Types of Wind Turbines}

There are two main types of wind turbines, namely, horizontal axis wind turbines (HAWTs) and vertical axis wind turbines (VAWTs). HAWTs use axial flow devices to operate in any wind direction. The tail vane or wind flow sensor rotates the wind turbine with the wind direction. The main components of HAWTs are the rotor blade and nacelle on top of the tower as shown in Figure 2. HAWTs are the most widely used type of wind turbines. VAWTs have blades running from the top to the bottom of the main vertical rotor shaft as shown in Figure 2. The system used to operate VAWTs in any wind direction is called the cross-device system. This type of wind turbine is best suited for use on top of buildings or on the ground. Maintenance is easy as the generator and gearbox are close to the base of the turbine; however, VAWTs are not as efficient as HAWTs (Hughes, 2019; Clarke, 2018).

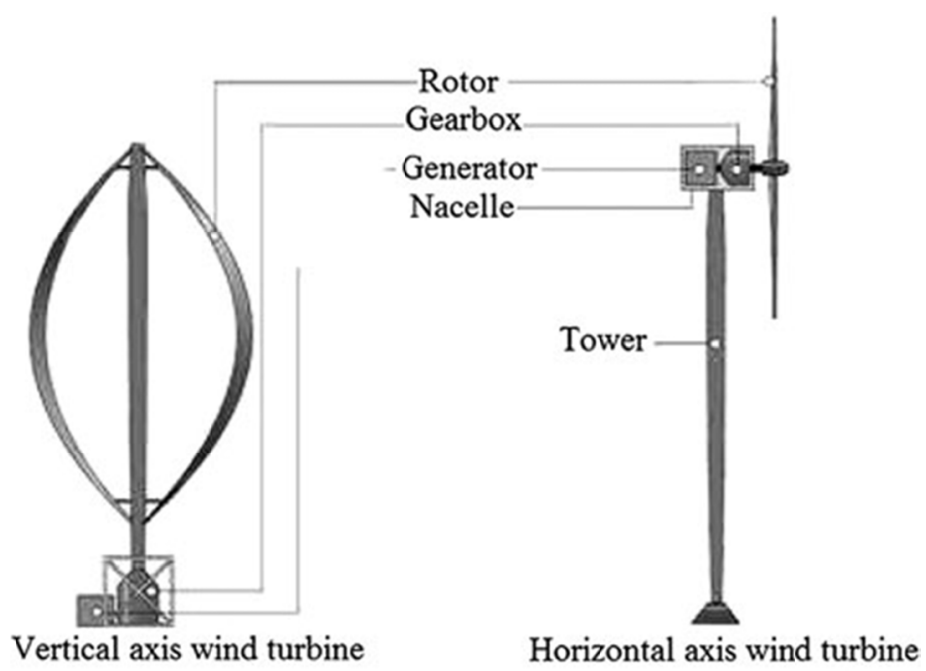

Figure 2. Types of wind turbines (Mahmoud \& Xia, 2012)

\subsection{Types of Floating Offshore Wind Turbines}

FOWTs capture the most wind energy since offshore wind speeds are higher than those on land. However, the floating platforms must be designed with several dynamic characteristics to withstand various offshore weather 
load conditions. Three types of FOWT platforms have been developed as both commercial and prototype systems including spar-buoy, spar-submersible, and tension-leg platforms as shown in Figure 3 (International Renewable Energy Agency [IRENA], 2016).

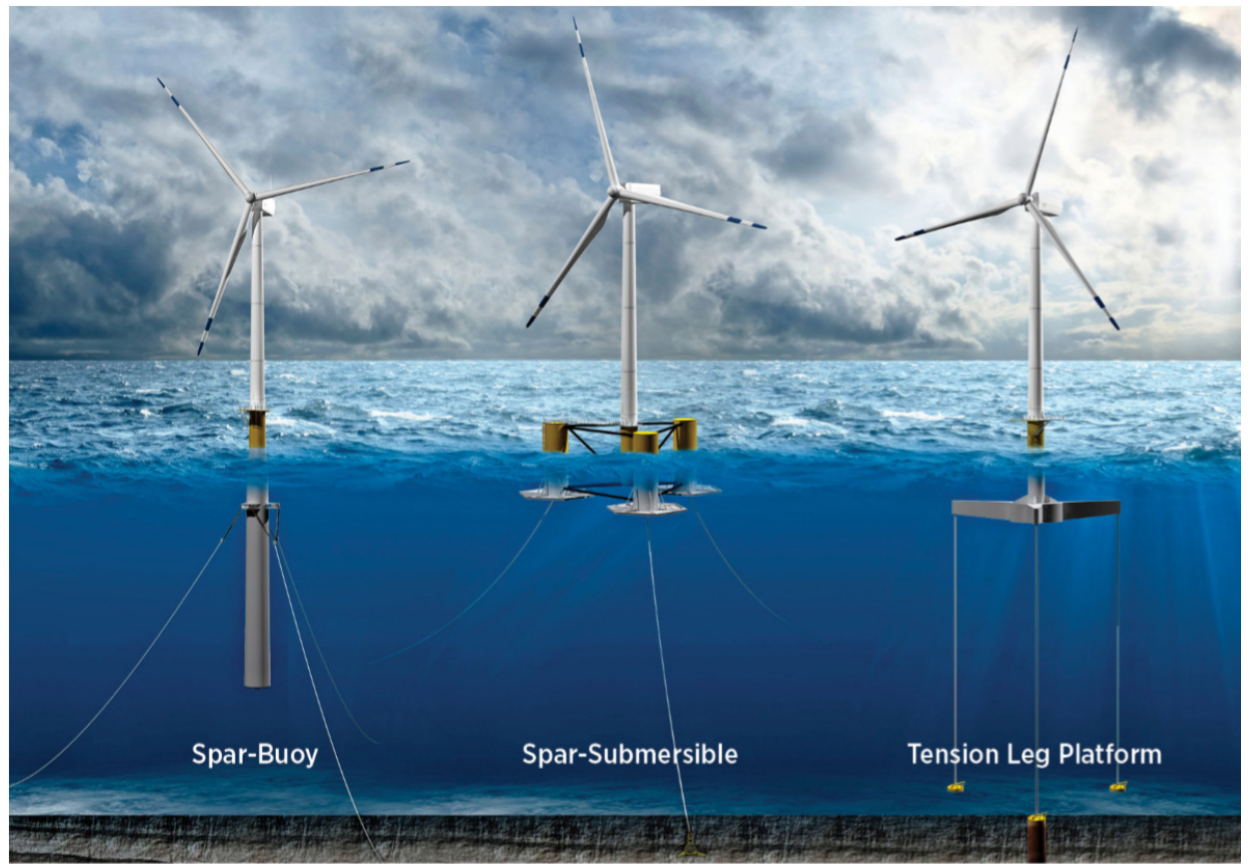

Figure 3. Design of floating offshore wind turbine concepts (International Renewable Energy Agency [IRENA], 2016)

The spar buoy has a cylindrical shape with ballast at the bottom of the platform to ensure that it floats and stays upright with a center of gravity below the center of buoyancy. The lower parts of the structure are heavy and the upper parts are usually lighter, thereby raising the center of buoyancy. These platforms require deep water as the draft of the platform is higher than or equal to the hub height above mean sea level. This ensures stability and reduces heave motion. Hence, assembly, transportation, and installation processes are quite challenging (Carbon Trust, 2015). Recently, the Hywind Scotland Wind Farm installed five spar buoy wind turbines with a total capacity of $30 \mathrm{MW}$ in the North Sea to provide electricity to approximately 22,000 homes (Froese, 2018).

A semi-submersible platform is connected by large columnar tubes. The wind turbine is mounted on one of the columnar tubes, or mounted at the geometric center of the platform, and supported by bracing members. The columnar tubes act as ballast to provide stability in the water. This structure is simple to install (Carbon Trust, 2015). In 2011, a semi-submersible platform prototype called WindFloat 1 was launched by Principle Power, Inc. off the coast of Aguçadoura, Portugal with a capacity of 2 MW. The next generation of WindFloat will be developed for capacities of up to $8 \mathrm{MW}$ (Banister, 2017). Another prototype called VolturnUS 1:8 was successfully deployed by the University of Maine off the coast of Castine, Maine in 2013. It is 1:8th the geometric scale of a $6 \mathrm{MW}$ wind turbine as the first grid-connected offshore wind turbine in America (Dagher, 2017).

The tension-leg platform is a semi-floating structure with stability created by the tension of the mooring lines anchored to the seabed. These structures are smaller and lighter due to the low draft and tension stability but this design increases stress on the tendon and anchor system. There are also challenges in the installation process with increased operational risks if a tendon fails (Carbon Trust, 2015). Recently, in 2018, the GICON-SOF floating offshore foundation was tested in the SSPA Maritime Dynamics Laboratory in Gothenburg, Sweden. An experimental model of 1:50-scale passed various wind tests, wave tests, the towing and transportation process, and the new anchoring process. Results could lead to successful operation in the future (OffshoreWind.biz, 2018).

\subsection{Floating Offshore Wind Turbine Loading Sources}

Two types of loads act on FOWTs including permanent actions (dead loads) and live loads as shown in Figure 4. Dead loads are gravitational loads associated with the self-weight of the structure and the weights of the tower 
internals.

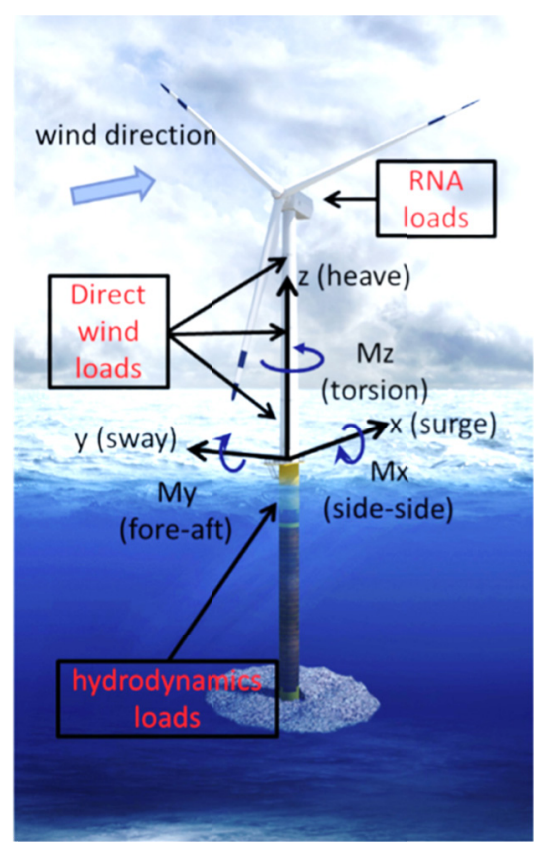

Figure 4. Offshore wind turbines loading sources (Damiani, 2016).

Live loads include the following:

- Aerodynamic loads from the rotor nacelle assembly (RNA) including forces and moments originating at the rotor and routed through the drive train and bedplate.

- Drag loads from direct wind action on the tower, and potential vortex shedding loads.

- Inertial loads associated with vibrational modes of the system caused by turbulence and wind shear, and the inertial and aero-structural properties of the rotor.

- Hydrodynamic loads on the floating platform such as waves, currents, and ice loads.

- Operational loads from control devices such as yaw, pitch, brake and torque control mechanisms.

\section{Methodology}

\subsection{Experimental Setup}

The experiments were conducted using a wind tunnel at the Rajamangala University of Technology Thanyaburi (RMUTT) Energy Research and Service Center. The wind tunnel with a 20,000 CFM centrifugal fan driven by a three-phase, $11 \mathrm{~kW}$ motor and a fan speed controller is shown in Figure 5. The wind tunnel was $3 \mathrm{~m}$ high, $4 \mathrm{~m}$ wide and $4.5 \mathrm{~m}$ long with a $1 \mathrm{~m} \times 1 \mathrm{~m}$ airflow channel. Water tank dimensions were $0.8 \mathrm{~m}$ height, $1.35 \mathrm{~m}$ width, and $1.4 \mathrm{~m}$ length.

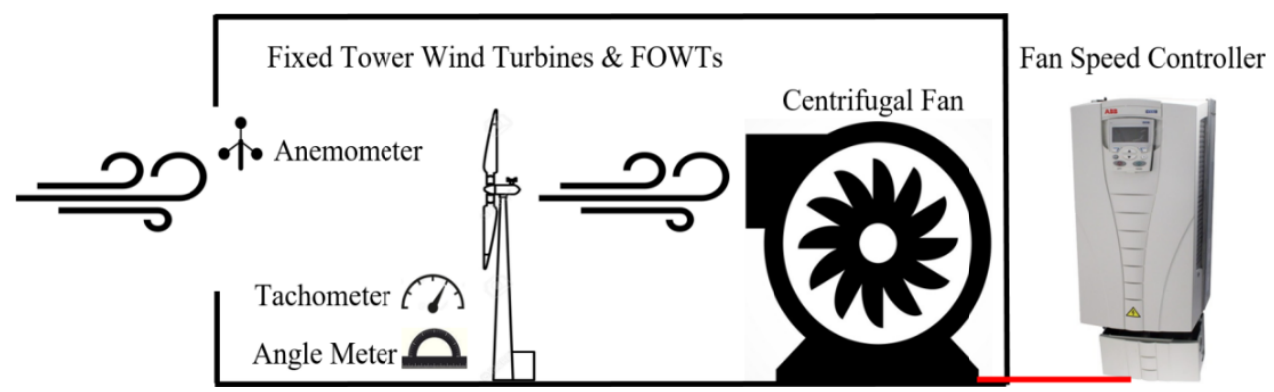

Figure 5. Schematic Diagram of Wind Tunnel. 
The aerodynamic performances of FOWTs were analyzed experimentally and computationally to compare performance results with fixed tower wind turbines having the same airfoil blade profile and diameter as shown in Figure 6. The experiment was set up in a wind tunnel to test the model under various wind speed conditions. A semi-submersible platform was selected due to its simple installation, excellent stability, and the limited space available in the wind tunnel. Dimensions of the FOWT and the experimental setup are shown in Figure 6 and Figure 7.

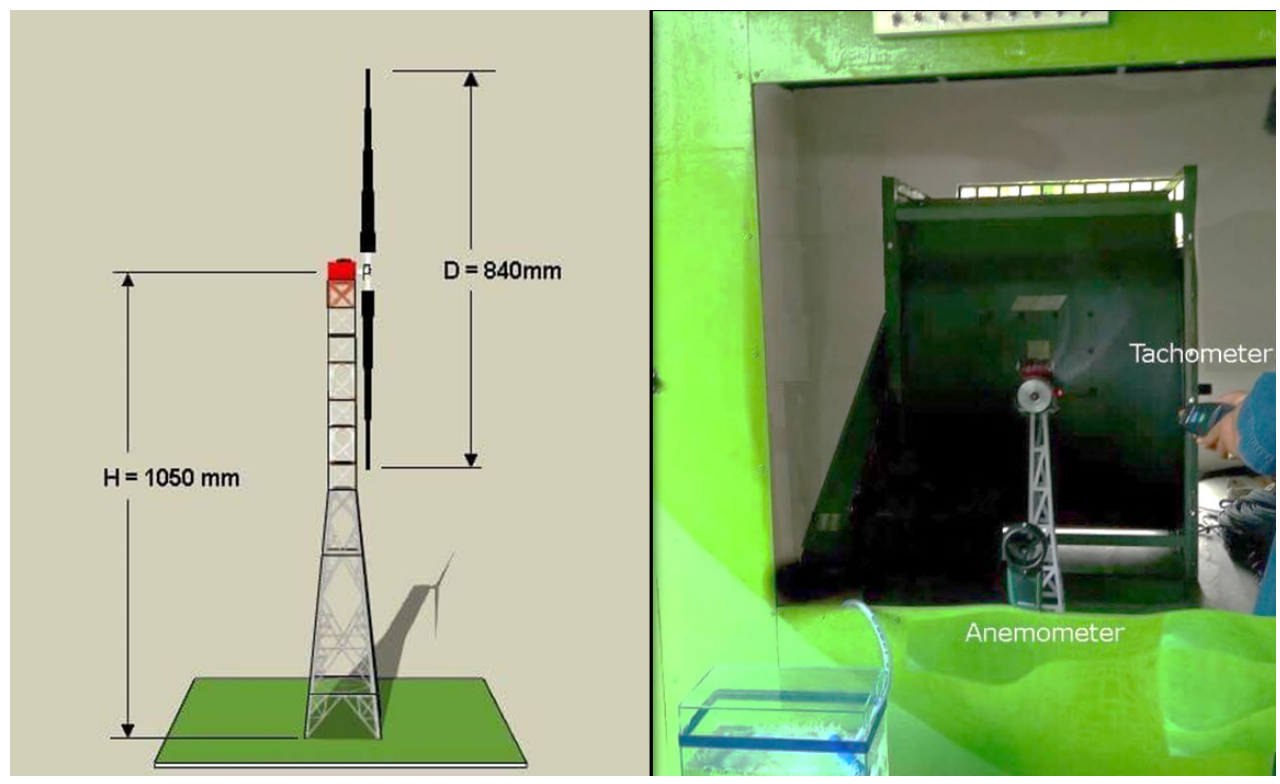

Figure 6. Fixed tower wind turbines setup in wind tunnel
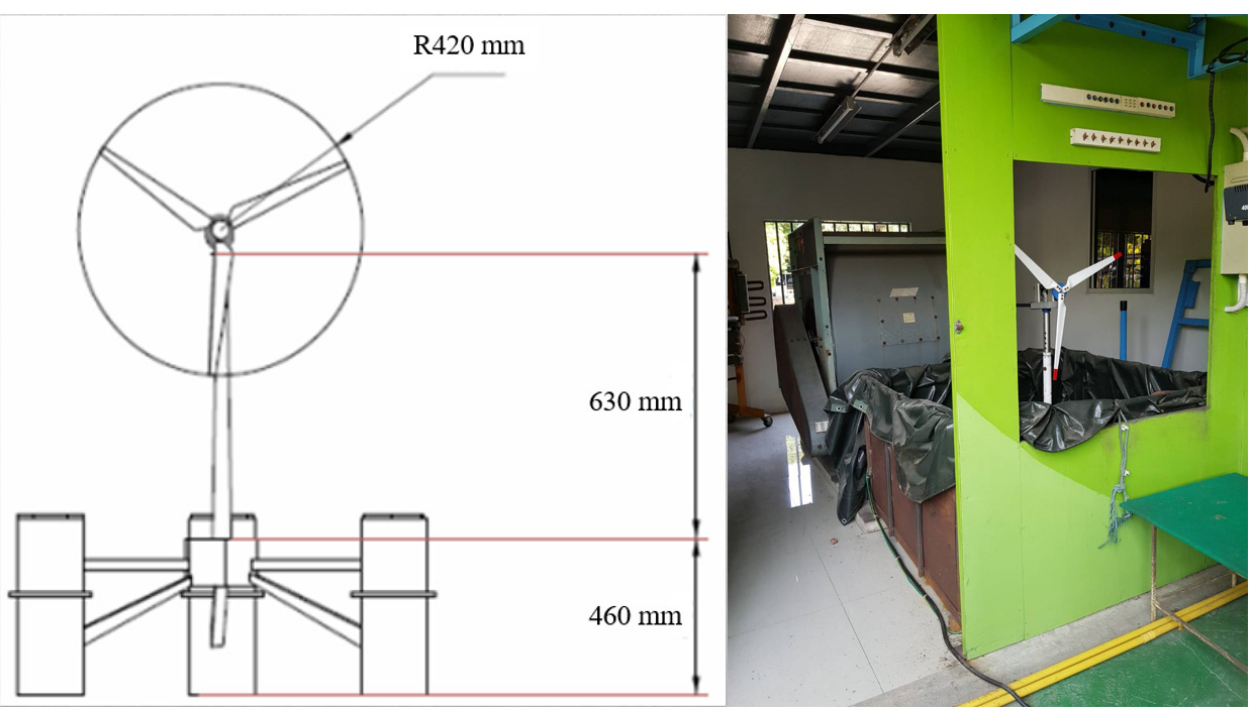

Figure 7. Floating offshore wind turbines setup in wind tunnel

Three measuring tools were used in the experiment. An anemometer measured wind speeds, a tachometer measured rotational speeds at different wind speeds, and an angle meter measured the tilt angle. The desired wind speeds were adjusted using the fan speed controller driving the motor of the centrifugal fan. The air was pulled in by the centrifugal fan creating wind which rotated the blade rotor of the fixed tower wind turbine and the FOWT setup.

The airfoil blade profile is an important factor in determining the efficiency of power production of the wind turbines at various wind speeds. The R1235 airfoil was selected for this experiment. This model is designed to operate in low wind speed zones and produces a higher lift force in low Reynolds number flows. Hence, the 
cut-in wind speed of this airfoil is as low as $2 \mathrm{~m} / \mathrm{s}$ and it is suitable for low wind speed zones with average wind speeds of $4-5 \mathrm{~m} / \mathrm{s}$. Figure 8 compares the theoretical high speed wind turbine blade and the R1235 blade which has a higher tip speed ratio at the maximum power coefficient of 0.35 compared to the theoretical wind turbine blade.

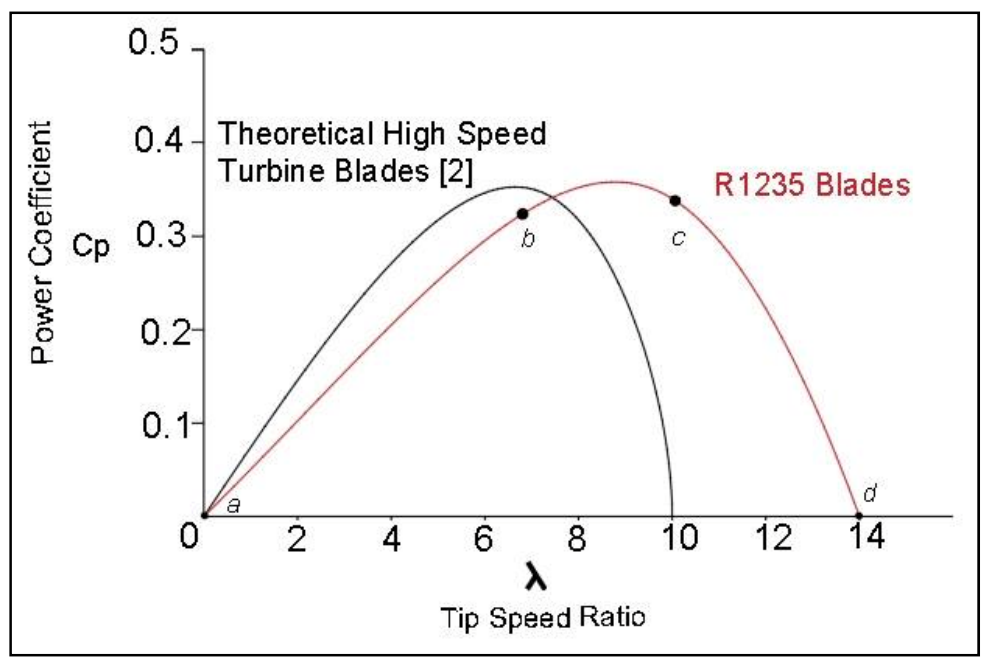

Figure 8. R1235 airfoil blade tip speed ratio (Roynarin, 2004)

\subsection{Measurement Methods}

Figure 9 shows the experimental setup and method to measure the wind speed, rotational speed, and the tilt angle of the FOWT using an anemometer, a tachometer and an angle meter, respectively. The wind speed was adjusted using the fan speed controller. This drives the motor of the centrifugal fan to achieve the desired speed. A wind speed range of $2-5.5 \mathrm{~m} / \mathrm{s}$ was required. Ten iterations were performed for each blade rotation at given wind speed.

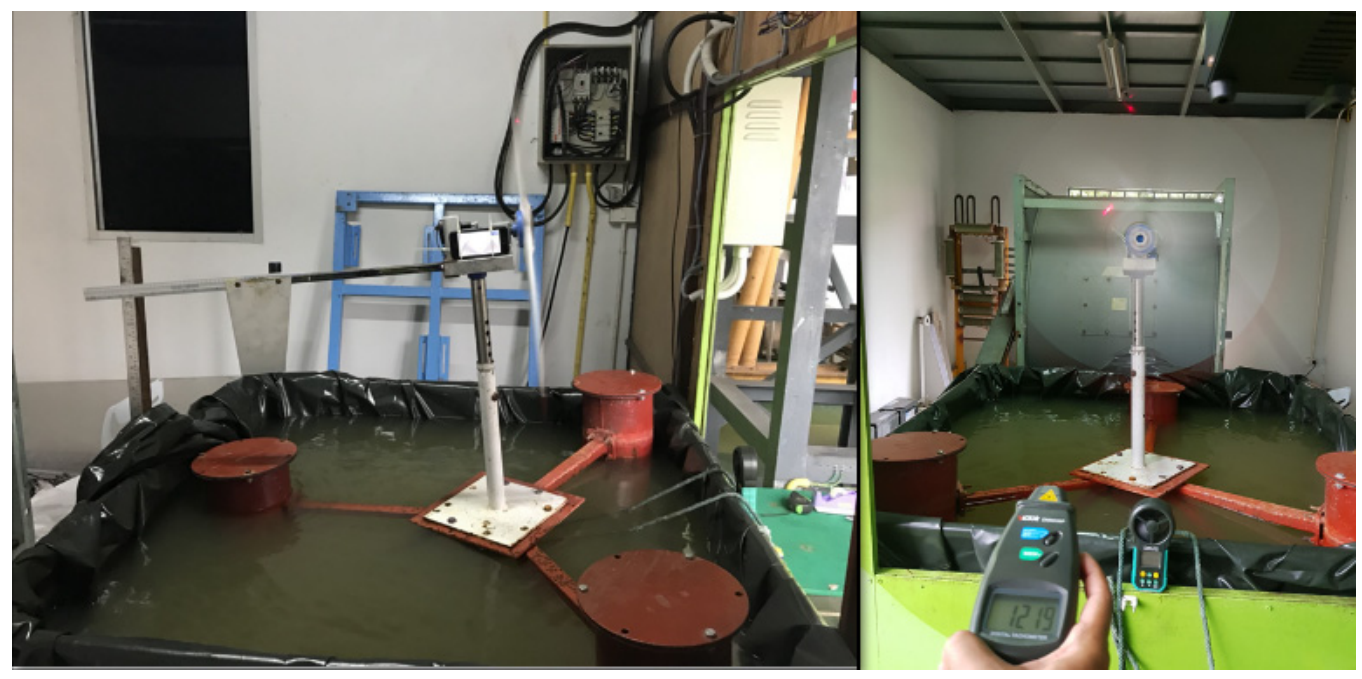

Figure 9. Measurement methods

\subsection{Measured Wind Turbine Parameters}

The following parameters were measured in the wind tunnel.

\subsubsection{Wind Speed}

Wind speed is one factor that influences power output and number of rotations of the blade. The setup used wind speeds of 2-5.5 m/s which matched the range of wind speed in Thailand. 


\subsubsection{Rotational Speed}

Rotational speed as the number of revolutions per minute is one of the factors required to calculate the tip speed ratio of the wind turbine. Higher numbers of revolutions per minute rotate the blades faster to produce greater power output.

\subsubsection{Tilt Angle}

Tilt angle occurs from vertical misalignment of the turbine axis due to wind flow which moves the rotor away from the axis. This decreases the effective area of the rotor which reduces the amount of energy captured.

The following parameters were determined using theoretical equations for wind turbines.

\subsubsection{Tip Speed Ratio (TSR)}

TSR is the ratio between the speed of the rotor tip and the actual wind speed. This integrates the principle aerodynamic effect of wind speed, rotor size, and rotor angular speed with the power coefficient of the wind turbines rotor and is an important factor in maximizing the power generated from the wind. TSR can be written as: (Cao, 2011).

$$
T S R=U / V=\omega r / V=2 \pi r N / 60 \mathrm{~V}
$$

where $U$ is the speed of the rotor tip $(\mathrm{m} / \mathrm{s}), V$ is the wind speed $(\mathrm{m} / \mathrm{s}), \omega$ is the angular velocity $(\mathrm{rad} / \mathrm{s}), r$ is the rotor radius (m), and $N$ is the rotational speed of the rotor (rpm).

\subsubsection{FOWTs Power Output}

Wind turbines convert kinetic energy into electrical power. The power output depends on two main factors as the wind speed and the swept area of the turbine. The power output equation can be written following Manwell, McGowan, \& Rogers (2009):

$$
P_{W}=1 / 2 \rho A V^{3} C_{P}
$$

where $\rho$ is the air density $\left(1.225 \mathrm{~kg} / \mathrm{m}^{3}\right), A$ is the swept area $\left(\mathrm{m}^{2}\right), V$ is the wind speed $(\mathrm{m} / \mathrm{s})$, and $C_{P}$ is the power coefficient of the wind turbine.

In the power output equation, a reduction factor was included for the tilt angle to account for reduction in the effective area and energy capture. Figure 10 shows the tilt angle ( $\beta$ angle) that occurs in FOWTs due to the wind flow.

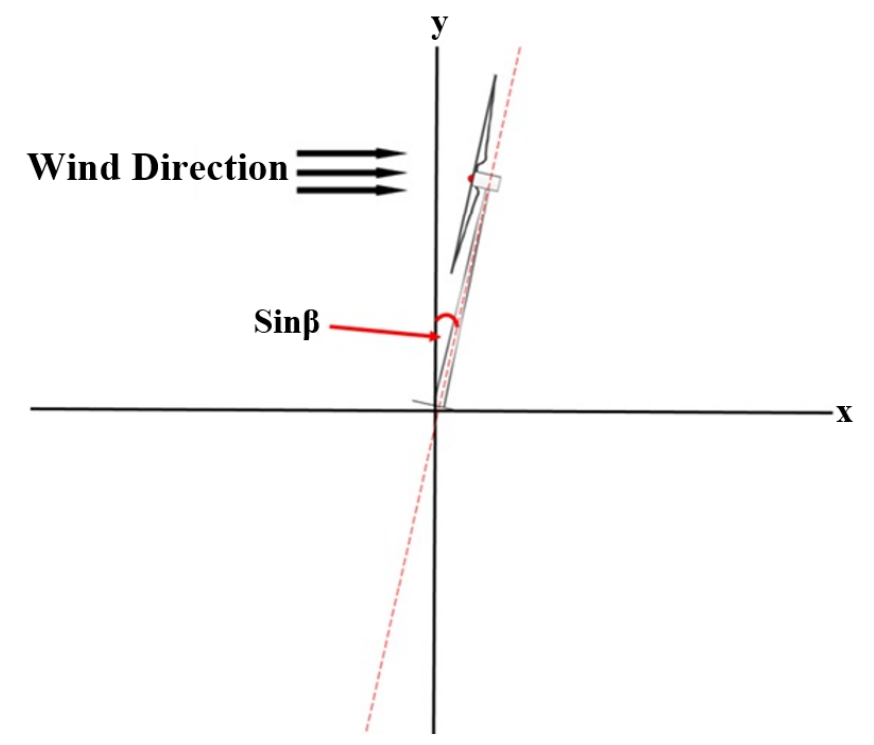

Figure 10. Assumption of tilt angle of FOWT

Assuming the wind turbine tower is perpendicular to the $\mathrm{x}$-axis, the initial value of the reduction factor is 1 which is equal to $\operatorname{Sin} 90^{\circ}$. When the wind turbine is tilted, the reduction factor decreases from its initial value and is equal to $\operatorname{Sin}\left(90^{\circ}\right.$ - tilt angle of the tower) as shown in Figure 10, and equal to the value of $\operatorname{Sin} \beta$. Therefore, the FOWT power output can be written as: 


$$
P_{\text {FOTW }}=1 / 2 \rho A V^{3} C_{P} \operatorname{Sin} \beta
$$

\section{Results and Discussion}

\subsection{Experimental Data Results}

Findings from the wind tunnel experiments are shown in Table 1 as fixed tower wind turbine results with wind speed and average rotational speed. Table 2 shows the FOWT experimental data including wind speed, rotational speed and beta angle.

Table 1. Fixed tower wind turbines experimental data

\begin{tabular}{cc}
\hline Wind Speed $\mathbf{( m / s )}$ & Rotational Speed $(\mathbf{r p m})$ \\
\hline 2.0 & 393.1 \\
2.5 & 591.6 \\
3.0 & 736.4 \\
3.5 & 904.0 \\
4.0 & 1043.9 \\
4.5 & 1241.6 \\
5.0 & 1483.0 \\
5.5 & 1608.9 \\
\hline
\end{tabular}

Table 2. FOWTs experimental data

\begin{tabular}{ccc}
\hline Wind Speed (m/s) & Rotational Speed (rpm) & Beta Angle (degree) \\
\hline 2.0 & 307.1 & $3.5^{\circ}$ \\
2.5 & 437.7 & $3.8^{\circ}$ \\
3.0 & 534.6 & $3.9^{\circ}$ \\
3.5 & 655.6 & $4.3^{\circ}$ \\
4.0 & 781.1 & $4.7^{\circ}$ \\
4.5 & 891.2 & $5.0^{\circ}$ \\
5.0 & 1010.8 & $5.8^{\circ}$ \\
5.5 & 1144.7 & $6.1^{\circ}$ \\
\hline
\end{tabular}

Both experimental data sets show that rotational speed was proportional to wind speed. As wind speed increased, rotational speed also increased. However, the FOWT rotational speed results were lower than the fixed tower wind turbine results due to the effect of the beta angle on the rotor wind turbine performance. 


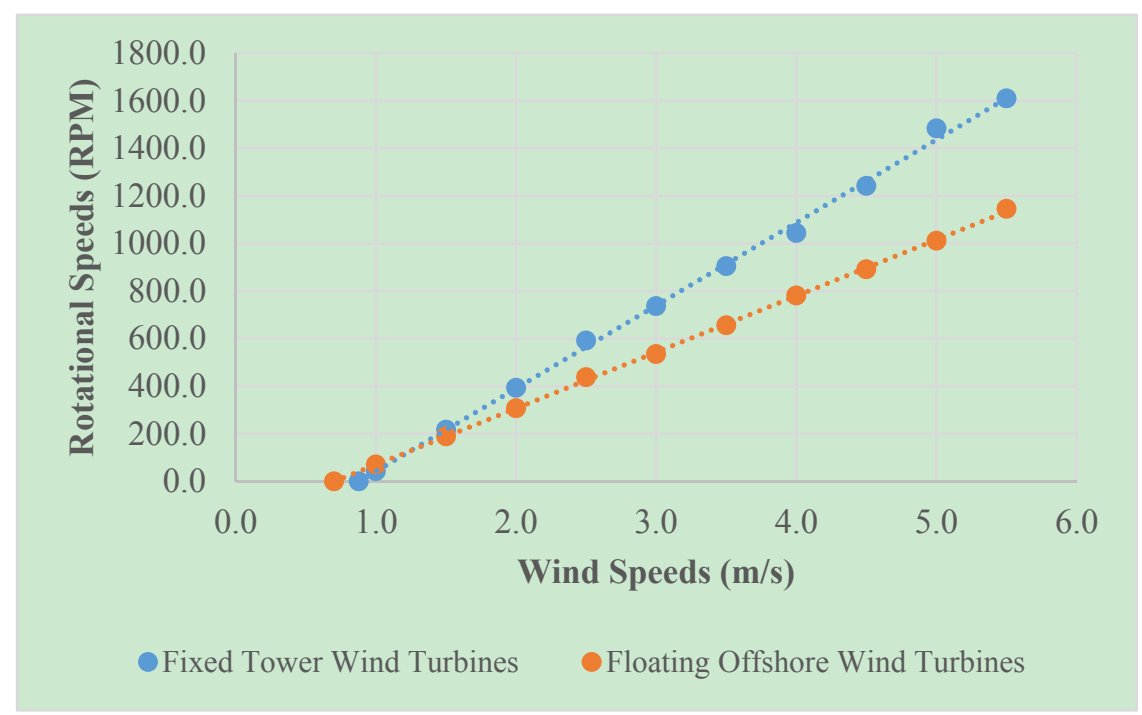

Figure 11. Comparison between a fixed tower wind turbine and FOWT

Table 3. Wind speed vs. reduction percentage

\begin{tabular}{cc}
\hline Wind Speed $(\mathbf{m} / \mathbf{s})$ & Reduction Percentage (\%) \\
\hline 2.0 & 22 \\
2.5 & 26 \\
3.0 & 27 \\
3.5 & 27 \\
4.0 & 25 \\
4.5 & 28 \\
5.0 & 32 \\
5.5 & 29 \\
\hline
\end{tabular}

Figure 11 shows the comparison of average rotational speed values between a fixed tower wind turbine and a FOWT at given wind speed. Trendline analysis was applied to fit the experimental data points and provide some correction by using linear fit. The graph shows that rotational speed results of the FOWT were lower than the fixed tower wind turbine due to the vertical misalignment of the rotor blade. Positioning of the wind turbine rotor is an essential factor for optimizing the direction of the incoming wind flow to maximize the efficient use of wind energy. Therefore, increasing the tilt angle away from the optimal setting decreased the wind energy captured. This result also has agreed with the studies of Gumula et al. in 2017. Reduction percentage of the rotational speed between the FOWT and fixed tower wind turbine is displayed in Table 3. Loss varied from $22 \%-32 \%$ with variation in wind speeds. Power output production was also significantly affected by the tilt angle. Changing angle of attack on the rotor blade occurred and the aerodynamic behaviors of the blade were altered from the optimal position. Moreover, the effective area of the rotor swept area varied and directly affected power output production.

All experiments were carried out at wind speeds from $2-5.5 \mathrm{~m} / \mathrm{s}$ due to the limitation of the wind tunnel to prevent potential risks from strong vibration of the whole apparatus and protect the equipment from damage.

\section{Conclusion}

Experiments were conducted on a R1235 airfoil blade to test the rotational speed performance of FOWTs and fixed tower wind turbines. Effects of tilt angle on the performance of both experimental models were studied. Results showed that the rotor blade tilt angle significantly influenced wind energy characteristics as an effective area for wind energy harvesting and performance. Additionally, reduction percentage occurred at a beta angle between $3.5^{\circ}-6.1^{\circ}$, resulting in loss of performance ranging from $22 \%-32 \%$ at various wind speeds.

Further research is required to investigate the specific power coefficient for each wind speed of the experimental 
models. Values of tip speed ratio and R1235 airfoil blade tip speed ratio graph at each wind speed would provide different power coefficients. Power output for both experimental models can be determined using wind power output equations with different power coefficients. Finally, our results of FOWTs should be compared between experimental models and computational fluid dynamics (CFD) in different turbulence models.

\section{Acknowledgement}

I would like to thank my supervisor, Asst. Prof. Dr. Wirachai Roynarin for supporting me and sharing his knowledge with me for this research. I would like to also thank Mr. Decha for giving me useful inputs while consulting him for this paper. I am deeply grateful to the team in the Energy Research and Service Center (ERSC) of the engineering faculty, RMUTT for providing the laboratory for the experiment. Finally, I would like to give all credit to my family who always support me.

\section{References}

Banister, K. (2017). Principle Power, Inc. WindFloat Pacific Project, Final Scientific and Technical Report. https://doi.org/10.2172/1339449

BP. (2018). BP Statistical Review of World Energy 67th Edition. Retrieved from https://www.bp.com/content/dam/bp/business-sites/en/global/corporate/pdfs/energy-economics/statistical-re view/bp-stats-review-2018-full-report.pdf

Burger, T. (2016). Pros and Cons of Floating Platforms in Marine Renewable Energy. Retrieved from https://pmiind.com/pros-cons-floating-platforms-marine-renewable-energy/

Cao, H. (2011). Aerodynamics Analysis of Small Horizontal Axis Wind Turbine Blades by Using 2D and 3D CFD Modelling. (Master's thesis, University of Central Lancashire, Preston, United Kingdom). https://doi.org/10.4314/ijest.v9i2.5

Carbon Trust. (2015). Floating Offshore Wind: Market and Technology Review. Retrieved from https://www.carbontrust.com/media/670664/floating-offshore-wind-market-technology-review.pdf

Clarke, S. (2018). Electricity Generation Using Small Wind Turbines at Your Home or Farm. Retrieved from http://www.omafra.gov.on.ca/english/engineer/facts/18-005.pdf

Dagher, H. (2017). The VolturnUS 1:8 Floating Wind Turbine: Design, Construction, Deployment, Testing, Retrieval, and Inspection of the First Grid-Connected Offshore Wind Turbine in US. https://doi.org/10.2172/1375022

Damiani, R. R. (2016). Design of Offshore Wind Turbine Towers. https://doi.org/10.1016/B978-0-08-100779-2.00010-6

Froese, M. (2018). World's First Floating Wind Farm Delivers Promising Results. Retrieved from https://www.windpowerengineering.com/business-news-projects/worlds-first-floating-wind-farm-delivers-p romising-results/

Gumula, S., Piaskowska, M. Pytel, K. and Noga, H. (2017). Evaluation of the Impact of Adjusting the Angle of the Axis of a Wind Turbine Rotor Relative to the Flow of Air Stream on Operating Parameters of a Wind Turbine Model. https://doi.org/10.1051/e3sconf/20171401016

Hughes, K. (2019). Solar Power vs. Wind Power Cost, Types, Pros \& Cons of Home Wind \& Solar. Retrieved from https://www.letsgosolar.com/consumer-education/solar-power-wind-power/

International Renewable Energy Agency (IRENA). (2016). Floating Foundations: A Game Changer for Offshore Wind Power. Retrieved from https://www.irena.org/-/media/Files/IRENA/Agency/Publication/2016/IRENA_Offshore_Wind_Floating_F oundations_2016.pdf

Jaber, S. (2013). Environmental Impacts of Wind Energy. Journal of Clean Energy Technologies, 1, 251-4. https://doi.org/10.7763/JOCET.2013.V1.57

Lehr, J. H., \& Keeley, J. W. (2016). Alternative Energy and Shale Gas Encyclopedia. New Jersey: Wiley Publication.

Lew, D. J. (2009). Environmental Impacts of Wind Power. Retrieved from http://www.eolss.net/sample-chapters/c09/e4-23-04-02.pdf

Mahmoud, M. S., \& Xia, Y. (2012). Applied Control System Design. London: Springer-Verlay London Limited.

Manwell, J. F., McGowan, J. G., \& Rogers, A. L. (2009). Wind Energy Explained (2nd ed.). West Sussex: John 
Wiley \& Sons Ltd.

National Renewable Energy Laboratory (NREL). (2011). State of the Art in Floating Wind Turbine Design Tools. Retrieved from https://www.nrel.gov/docs/fy12osti/50543.pdf

National Renewable Energy Laboratory (NREL). (2015). Wind Energy Benefits. Retrieved from https://www.nrel.gov/docs/fy15osti/62823.pdf

New Zealand Wind Energy Association. (2013). Benefits of Wind Farms. Retrieved from http://www.windenergy.org.nz/store/doc/BenefitsofWindFarms.pdf

OffshoreWind.biz. (2018). Gicon Floater Completes Transport and Installation Tests. Retrieved from https://www.offshorewind.biz/2018/10/12/gicon-floater-completes-transport-and-installation-tests/

Ponta, F. L., Otero, A. D., \& Rajan, A. (2016). Effects of Rotor Deformation in Wind-Turbine Performance: The Dynamic Rotor Deformation Blade Element Momentum Model (DRD-BEM). Renewable Energy, 92, 157-170. https://doi.org/10.1016/j.renene.2016.01.098

Renewable Energy Network for the 21st Century (REN21). (2018). Renewables 2018 Global Status Report. Retrieved from http://www.ren21.net/wp-content/uploads/2018/06/17-8652_GSR2018_FullReport_web_final_.pdf

Roynarin, W. (2004). Optimization of Vertical Axis Wind Turbines (Doctoral thesis, Northumbria University, Newcastle, United Kingdom). Retrieved from http://nrl.northumbria.ac.uk/1655/3/THESIS_WRoynarin_-_Optimisation_Vertical_Axis_Wind_Turbines_2 004.pdf

Roynarin, W. (2016). Development of $100 \mathrm{~kW}$ Small Wind Machine for the Floating Applications to Support the Island Energy Demand. In Proceeding of the 4th International Conference on Wind Turbine and Renewable Energy. Seoul, South Korea: Kangwon National University.

SNC-Lavalin Group. (2018). Offshore Wind Handbook. Retrieved from https://www.snclavalin.com/ /media/Files/S/SNC-Lavalin/documents/publications/o-g-offshore-wind-broch ure_en.pdf

The Department of Alternative Energy Development (DEDE). (2009). Wind Power and Its Potential in Thailand. Retrieved from http://weben.dede.go.th/webmax/content/wind-power-and-its-potential-thailand

Thorium Energy World. (2017). World Energy Situation. Retrieved from $\mathrm{http}: / /$ www.thoriumenergyworld.com/energy.html

Waewsak, J., Landry, M., \& Gagnon, Y. (2015). Offshore Wind Power Potential of the Gulf of Thailand. Renewable Energy, 81, 609-26. https://doi.org/10.1016/j.renene.2015.03.069

\section{Copyrights}

Copyright for this article is retained by the author(s), with first publication rights granted to the journal.

This is an open-access article distributed under the terms and conditions of the Creative Commons Attribution license (http://creativecommons.org/licenses/by/4.0/). 